\title{
Participation in Practice: A comparative Evaluation of Community Members' Level of Involvement in Management of Rural and Urban Forests in Kenya
}

\author{
Victor K. Boiyo, Jane M. Mutune, James K. Kiemo
}

\begin{abstract}
Participatory system of governance entails involvement of stakeholders in the process of policy formulation, implementation and decision making. Studies done on the subject of participation in forest management has considered participation in general without going into the details of level of participation and decision making. Furthermore, this studies have had a bias on participation in rural set up and thus there is little that has been documented on participation in the context of urban forests. This study was conducted to establish the level of CFA members' participation and decision making in rural forests as compared to urban forests. Kiptuget Forest in Baringo County and Ngong Road Forest in Nairobi City County were purposefully selected to represent rural and urban forests respectively. The study employed both primary data collected using questionnaires and key informants interviews and secondary data collected from review of PFM technical reports, articles, and publications. Data was analyzed using percentages, statistical measures of central tendencies, tabulations, frequencies and Analysis of Variance (ANOVA).The study revealed that that NRFA had more regular and well attended meeting compared to KICOFA where meetings were only held when necessary. It was further established that majority of the members of NRFA $(41.5 \%)$ were engaged at a consultative level of decision making while majority of members of KICOFA (65.4\%) were involved at an informative level of decision making. It was also noted that due to its better financial capacity, NRFA had managed to hire scouts to help in monitoring and enforcement of forest regulations. The study recommends that the legislature should work on reviewing the legal framework and regulations governing PFM implementation to grant more decision making powers to the CFA, the CFAs and KFS should work together to build the capacity of CFAs for them to effectively participate in co management of the forest.
\end{abstract}

Index Terms - Forest Governance, Participation, Practice

\section{INTRODUCTION}

Several developing countries particularly in Africa and Asia in the past three decades have adopted participatory forest management approach where the forest adjacent community are integrated in the programmes of forest management (Coulibaly-Lingani, 2016). In this approach of forest management, a community has been conceived to be a group of individuals who have common and shared perspectives which precipitate joint activity within a given spatial, socio-cultural or socio-economic contexts

Victor Kiprotich Boiyo, Wangari Maathai Institute for Peace and Environmental Studies, University of Nairobi, Kenya

Dr. Jane Mutheu Mutune (PhD), Wangari Maathai Institute for Peace and Environmental Studies, University of Nairobi, Kenya.

Dr. James Karatu Kiemo (PhD), Department of Sociology and Social Work, University of Nairobi, Kenya.
(Coulibaly-Lingani, 2016). Participatory forest management approach has been termed as community forestry and considered a situation that intimately involves local people in forestry activity (FAO, 2016). The concept is also considered in terms of common property management regime whose goal is to involve the local community and their interests with a view of achieving sustainability (Taylor, 2000; Sikor, 2006).

In the context of Kenyan legal framework, the Forests Conservation and Management Act 2016, considers community as a clearly defined group of users of forests identified on the basis of ethnicity, culture or similar community. Likewise, forest community is considered a group of persons who have a traditional association with a forest for the purposes of livelihood, culture or religion. Similarly, the act recognizes community forest association (CFA) as a group of local persons who have registered an association for the purposes of participating in forest management (Government of Kenya, 2016). Through the CFAs, the community members co-manage forest resources together with the Kenya Forest Service under the Participatory Forest Management framework (PFM).

Several studies (Ongugo et al., 2008; Koech et al., 2009) done on Community Forest Associations (CFA) in Kenya focused on adoption, roles, challenges and opportunities and its impact on forest. These studies have focused on CFAs located in rural parts of Kenya and thus the findings and conclusions made may not necessarily reflect the status of CFAs in urban areas. This study was undertaken to compare the participation level of members in CFAs in urban and rural forests.

\section{THEORETICAL FRAMEWORK}

The concept of participation in any form of governance entails the direct or indirect engagement and involvement of people (Quick and Bryson, 2016). The uniqueness surrounding different contexts of participation yields different levels of engagement between actors will be realized. This attribute will result to different levels of participation which ultimately determines the outcome of the participation process (Potts et al., 2016). Studies and research done by World Bank postulates and describes four categories of participatory governance. These include information sharing level where the service providers inform locals about the project with an aim of facilitating or prompting action 


\section{Participation in Practice: A comparative Evaluation of Community Members' Level of Involvement in Management of Rural and Urban Forests in Kenya}

from the locals; consultation level where people are consulted on key issues of the project giving them an opportunity to interact and provide feedback; decision making level where beneficiaries have a decision making role in matters of program design and implementation and finally initiating level which is a proactive level of engagement that allows local communities to take the initiative in terms of actions or decisions pertaining to a project (World Bank, 2001).

CFAs is an entity that gives forest adjacent community members a platform upon which they participate in forest management in Kenya. It is in this entity that the framework of community participation is established in form of forest management agreement. In the context of this study, the researcher seeks to establish the level at which CFA members are engaged in participation and decision making in forest management

\section{MATERIALS AND METHODS}

Submit your manuscript electronically for review. The study was conducted in Ngong Road Forest in Nairobi City County and Kiptuget Forest-a section of Mau complex located in Baringo County. The main reasons for selecting this forest station is that by location, Kiptuget forest is located in rural area while Ngong' Road forest is within Nairobi metropolitan 6 kilometers from the Central Business District. The two sites thus ably represented rural and urban typology of the study.

The study adopted a comparative study methodology. In responding to the objectives of the study, the study targeted members of community forest associations. The study population involved 83 members and 125 members of NRFA and KICOFA respectively thus a study population of 208 CFA members from KICOFA and NRFA.

Data was collected through administration of questionnaires to CFA members. Qualitative information gathered through interviews and informal discussions was transcribed and analyzed using content analysis and summaries made according to the respective subjects. Quantitative data collected was analyzed using descriptive statistics including frequencies, percentages, means and cross tabulation. In drawing comparisons of variables between KICOFA and NRFA analysis of variance of 0.05 level of confidence was used. Data presentation has been done through description and tabulation

\section{RESULTS AND DISCUSSIONS}

For the purposes of participation in forest management, community members in both Ngong Road and Kiptuget forest had formed and duly registered Community forest Associations (CFAs) as prescribed in the Forest Conservation and Management Act, 2016. At the time of research, all the CFAs had valid registration certificate, approved forest management plan and forest management agreement signed by CFAs and Kenya Forest Service (KFS). Ngong' Road Forest Association (NRFA) in Nairobi City County and Kiptuget Community Forest Association (KICOFA) draws its membership from the community living adjacent to the forests.

\section{A. Participation in Practice}

Key informants' interview revealed that Ngong Road Forest Association (NRFA) had regular meetings where members met twice in a month. The researcher had an opportunity to be in one of the meetings and made observations of how the meetings were conducted. The meetings were attended by the members of the local community and not the corporate bodies and NGOs which are part of NRFA. The agenda of the meetings focused on the activities of the local community both conservation and income generating. On the other hand it was realized that KICOFA had no document or evidence of regular meetings. According to KICOFA officials, meetings are only held whenever it was necessary.

Meetings and public engagement are some of the fundamental tool used in participative governance. In order to ensure that the tool is effectively used, there is need to ensure that CFAs are in a position to conduct consistent meetings. Thus the KFS together with CFA officials needs to put mechanism in place to ensure that there are regular CFA meetings especially in rural CFAs. In order to achieve this, there is need to introduce incentives for meeting attendance e.g. trainings, capacity building workshops and operationalization of user groups.

The survey sought to find out at what level of decision making are the members in NRFA and KICOFA involved and the results are as shown in the table 1 ;

\begin{tabular}{|c|c|c|}
\hline Members' Participation in Meetings & $\begin{array}{l}\text { NRFA } \\
(\%)\end{array}$ & $\begin{array}{l}\text { KICOFA } \\
(\%)\end{array}$ \\
\hline Present in meeting and not making contribution & 6.0 & 29.4 \\
\hline $\begin{array}{l}\text { Opinion sought-without guarantee of } \\
\text { influencing decisions }\end{array}$ & 34.9 & 32.0 \\
\hline Expressing opinions \& taking initiatives & 39.9 & 7.0 \\
\hline Having voice to influence decisions & 9.1 & 2.0 \\
\hline Volunteering to undertake tasks & 10.0 & 26.4 \\
\hline Others & 0.0 & 3.2 \\
\hline \multicolumn{3}{|l|}{ Decision Making } \\
\hline \multirow{2}{*}{$\begin{array}{l}\text { Are you in some way } \\
\text { involved in decision } \\
\text { making in CFA } \\
\text { matters? }\end{array}$} & 98.8 & 87.2 \\
\hline & 1.2 & 11.8 \\
\hline $\begin{array}{l}\text { I am informed of } \\
\text { decisions made }\end{array}$ & 31.7 & 65.4 \\
\hline $\begin{array}{l}\text { If Yes, At what level } \\
\text { are you involved }\end{array}$ & 41.5 & 27.7 \\
\hline $\begin{array}{l}\text { I am fully involved in } \\
\text { the process of decision } \\
\text { making }\end{array}$ & 26.8 & 4.9 \\
\hline
\end{tabular}

In participatory forest management, the attendance of meetings is not by itself a demonstration of quality of participation of members. This is because members may attend meeting but not engage substantially in the business of meetings making the engagement one-sided and inundated with input only from those community members or stakeholders who have a strong opinion negating the principle of participative governance.

The results in table 1 reveals that majority of the members of KICOFA (32.0\%) participate at the level of opinion sought 
-without guarantee of influencing decisions while majority of NRFA members (39.9\%) participate at the level of expressing opinions and taking initiatives. This finding imply that members of NRFA are engaged in higher level of decision making as compared to members of KICOFA. It can be argued that this is attributable to high level of engagement of NRFA members in more and well attended meetings as compared to KICOFA where there are not only inconsistent but poorly attended meetings.

In regards to decision making, the results in table 1 reveal that that majority of members both in KICOFA and NRFA indicate that they are in some way involved in decision making in the CFA. However, by categorizing decision making levels to information, consultation and involvement, the findings of decision making levels majority of the members in NRFA $(41.5 \%)$ are involved at the consultation level of decision making while majority of members of KICOFA (65.4\%) are involved at the information level.

According to Kauzya, 2007, participation mechanism in devolved governance system can largely be categorized into vote and voice where vote is the means through which citizens select their representatives while voice is where citizens have the opportunity to influence decisions that affect them. Participation is optimal only when both the vote and voice mechanisms are optimized. As such participation of CFA members in meetings and decision making is important in the performance of PFM. In light of the aforementioned, it can be concluded here that NRFA has a higher performance capacity courtesy of its high level of involvement in meetings as well as higher level of involvement in decision making. This findings is in agreement with (Robinson, 2007) who pointed out that higher level of members participation yields higher performance of decentralized governance system. However, other studies have pointed out that in as much as this may be the case, there are other factors that may be equally influential, and hence attributing the local service delivery outcomes singly on citizen participation is a difficult task. In this the influential potential of citizen participation is only unleashed when other enabling factors are addressed including political, institutional, financial and technical factors (Yang and Pandey, 2011).

In a participative governance system, it is important that all stakeholders are substantively involved in decision making. This is very important in ensuring that the players own the decision of the process and thus make the process of implementation easy. This study reveals that there is need for state agency to grant the CFAs more decision making powers particularly in rural areas. Ideally, PFM should work towards achieving initiative level of decision making. This means that the community are empowered to be able to initiate ideas, projects, proposals and actions in the context of forest co-management.

In order to compare the level of participation in NRFA and KICOFA, , the researcher conducted analysis of variance (ANOVA) with a view of establishing the level of significance difference in the practice of CFA members' participation in NRFA and KICOFA. The analysis of variance considered members participation i.e. meetings, elections and decision making and CFA engagement with
KFS i.e. joint monitoring and enhancement of enforcement of forest rules and regulations. The results of ANOVA using 0.05 confidence level is as shown in table 2

\begin{tabular}{|l|c|}
\hline Area of Participation & P-Value \\
\hline Members' frequency of attending meetings & .00 \\
\hline Participation in CFA meetings & .98 \\
\hline Participation in CFA election of leaders & .11 \\
\hline Participation in decision making in CFA & .00 \\
\hline Level of Decision Making involved & .00 \\
\hline
\end{tabular}

The comparison of participation variables in KICOFA and NRFA as presented in table 12 reveal that in the variables of frequency of attending meetings $(\mathrm{p}=0.00)$ participation in decision making $(\mathrm{p}=03)$, level of decision making $(\mathrm{p}=0.00)$ and participation in joint monitoring $(\mathrm{p}=0.02)$ the $\mathrm{P}$ values are less than $0.005(\mathrm{P}<0.05)$. This implies that that in these variables of participation there is statistically significant difference in the participation practice in KICOFA and NRFA. In the other variables i.e. participation in CFA meetings and election of CFA leaders the results reveal that the $\mathrm{P}$ values was greater than $0.05(\mathrm{P}>0.05)$. This implies that in these variables, there was no statistically significant difference in participation practice in NRFA and KICOFA.

\section{CONCLUSIONS AND RECOMMENDATIONS}

NRFA had more regular and well attended meeting compared to KICOFA where meetings were only held when necessary. Majority of members of NRFA were engaged at a consultative level of decision making while majority of members of KICOFA were involved at an informative level of decision making. In light of the observations made in the study it is recommended that participatory forest management stakeholders led by the legislature should work on reviewing the legal framework and regulations governing the establishment and operations of CFAs in order to grant more powers to the CFA in the process of decision making. The CFA should deliberately be moved from the information sharing level of decision making to consultative and involvement level. This can be easily achieved by strengthening county governments and their working with CFAs. This will ensure that the laws and rules made will be more specific in terms of location, culture, gender, livelihood and other factors that are critical in PFM. Furthermore, the CFAs and KFS should work together to build the capacity of CFA members for them to effectively participate in co management of the forest. This will involve building their technical capacity, financial capacity, human capacity and social capacity through seminars, workshops, onsite training and exchange programmes.

\section{REFERENCES}

[1] Coulibaly-lingani, P. (2016). Appraisal of the participatory forest management program in southern Burkina Faso.Centre National de Recherche Scientifique.

[2] GOK, (2016) The Kenya Forest Conservation and Management Act, 2016

[3] Kauzya, J.M., (2007). Political Decentralization in Africa: Experiences of Uganda, Rwanda and South Africa. In: Cheema, G.S. \& Rondinelli, 
D.A., eds. 2007. Decentralizing Governance: Emerging Concepts and Practices. Washington: Brookings Institution Press. Pp. 75-91

[4] Koech, C. K, Ongugo, P. O., Mbuvi, M. T. E., and Maua, J. O. (2009).

Community Forest Associations in Kenya: challenges and opportunities. Kenya Forestry Research Institute.

[5] Ongugo, P.O.,Mogoi, J.N., Obonyo, E., Oeba, V.O., 2008. Examining the roles of community forest associations in the decentralization process of Kenyan forests. Paper Presented to the IASC Conference 11-19th July 2008, England

[6] Potts, R., Vella, K., Dale, A., and Sipe, N. (2016). Evaluating Governance Arrangements and Decision Making for Natural Resource Management Planning: An Empirical Application of the Governance Systems Analysis Framework. Society \& Natural Resources an International Journal, 1920(January 2017) https://doi.org/10.1080/08941920.2016.1185557

[7] Quick, K. S., and Bryson, J. (2016). Theories of public participation in governance, 20(February), 161-176.

[8] Robinson, 2007. Does decentralization improve equity and efficiency in public service delivery provision? IDS Bulletin. Volume 38 Number 1 January 2007. Pp. 7-17. [Online]Available at http://onlinelibrary.wiley.com/doi/10.1111/j.17595436.2007.tb00333.x/pdf

[9] Sikor, T. (2006). Analyzing community-based forestry: Local, political and agrarian perspectives. Forest Policy and Economics 8(4), 339-349.

[10] Talley, J., L., Schneider, J., Lindquist, E., (2016). A simplified approach to stakeholder engagement in natural resource management: the Five-Feature Framework; Ecology and Society

[11] Taylor, D. E. (2000). The rise of the environmental justice paradigm. American Behavioral Scientist, 43(4), 508-580.

[12] World Bank (2001). "A Revised Forest Strategy for the World Bank Group" (draft). 30 July 2001. Washington D.C. Cited in Vedeld et.al. (2004). Counting on the environment, Forest Environmental Incomes and the Rural Poor. Environmental Economics Paper No. 98. The International Bank for Reconstruction and Development. World Bank, Washington D.C.

[13] Yang, K., and Pandey, S.K., (2011). Further Dissecting the Black Box of Citizen Participation: When does Citizen Involvement Lead to good outcomes? Public Administration Review. Volume 71, Issue 6, pp. 880-892, November/December 2011. [Online]Available at http://onlinelibrary.wiley.com/doi/10.1111/j.1540-

6210.2011.02417.x/pdf 